\title{
Socio-demographic determinants of stigma among patients with pulmonary tuberculosis in Lagos, Nigeria
}

\author{
*Abioye $\mathrm{IA}^{1}$, Omotayo $\mathrm{MO}^{2}$, Alakija $\mathrm{W}^{3}$
}

1. Department of Medicine, Lagos State University Teaching Hospital, Ikeja, Lagos.

2. Healthitude International (Nigeria Office), Centre for African Resources Research and Development, Lagos.

3. Department of Community Health \& Primary Health Care, Lagos State University College of Medicine, Ikeja, Lagos, Nigeria

\begin{abstract}
Background: Patients living with tuberculosis (TB) experience significant disruption of their social life and are exposed to stigma and discrimination. This situation impacts on treatment adherence by individual patients and on disease control especially in developing nations. Different aetiological propositions have been propounded, including the relationship of tuberculosis with the Acquired Immune Deficiency Syndrome (AIDS).

Objectives: We sought to evaluate self-reported stigma experience among TB patients in Lagos and examine its sociodemographic determinants.

Method: This was a descriptive cross-sectional study, recruiting 205 patients on treatment at two government-owned referral centres for tuberculosis, using self-administered questionnaires to collect each respondent's data.

Result: Eighteen percent reported a previous stigma experience. Stigma experience was observed to be significantly determined by age, low socio-economic status, level of education below secondary level, disclosure of status, history of weight loss, previous smoking and alcohol history. Also, patients unable to work on clinic days were more likely to experience stigma. Sexs, religion, marital status and ethnicity were not significant determinants.

Conclusion: Experience of stigma among patients with tuberculosis is common and may adversely affect treatment adherence. Healthcare workers and policy makers need to pay closer attention to the identified determinants for effective tuberculosis control.
\end{abstract}

Keywords: Tuberculosis, AIDS, stigma, disclosure, weight loss

African Health Sciences 2011; 11(S1): S100 - S104

\section{Introduction}

Effective control of tuberculosis (TB) has been an arduous international health challenge. The disease infects $8-10$ million annually ${ }^{1}$ and is currently the $7^{\text {th }}$ leading cause of death worldwide ${ }^{2}$. The disease burden is greatest in Africa and Nigeria ranks fourth among twenty-two high burden countries ${ }^{3}$. TB is a chronic disease, presenting with prolonged cough and, like Acquired Immune Deficiency Syndrome (AIDS), with marked cachexia as common presenting symptoms. It leads to significant disruption of patients' life and predisposes patients to stigma and discrimination. Patients experience personal threat, social rejection and social stigma ${ }^{4}$, with women being worse hit ${ }^{5}$.

Stigma, according to Goffman, is an 'attribute that is deeply discrediting' and that reduces
*Corresponding author
Abioye Ibraheem Ajibola
Department of Medicine
Lagos State University Teaching Hospital
Ikeja, Lagos, Nigeria
Email:abiovez@yahoo.com

the bearer from 'a whole and usual person to a tainted, discounted one' ${ }^{6}$. Link and Phelan further define stigma as existing 'when a person is identified by a label that sets the person apart and links the person to undesirable stereotypes that result in unfair treatment and discrimination's. Different propositions have been propounded concerning the aetiology of stigma. Fear of being infected is an obvious cause of discrimination ${ }^{6}$, while scientifically unfounded beliefs about the transmission of the disease have been found to be significant predictors of stigma ${ }^{7}$. Stigma leads to discrimination, which is the 'unfair treatment of one person or group usually because of prejudice' about a specific character they possess ${ }^{8}$. Stigma and discrimination may affect the extent to which the patient is able to obtain, maintain and complete treatment ${ }^{9}$. In Ethiopia, stigma was found to be the major cause of non-compliance in the population ${ }^{10}$.

There is increased understanding of the need for emphasis on social and behavioural issues in $\mathrm{TB}$ 
control, for clinical success to be achieved. Most studies on this subject have assessed the common patterns of stigma among TB patients ${ }^{4,6,7}$, but not the determinants of this social ill. The goal of this study was to evaluate $t$ self-reported stigma experience among TB patients in Lagos, as well as examine its socio-demographic determinants.

\section{Methods}

The study locations were the Chest Clinics of the Lagos State University Teaching Hospital (LASUTH), Ikeja and the Mainland Hospital (formerly Infectious Disease Hospital [IDH]), Yaba. Both are referral centres for tuberculosis care in Lagos, owned by the state government. This was a descriptive crosssectional study, conducted in July 2008, recruiting all patients who had commenced treatment for up to a week. Data collection was quantitative, with the aid of 205 pre-tested self-administered questionnaires. Nineteen questions concerning the clinical history, socio-demographic variables and patient-reported experience of stigma were employed for this study. Patients with limited literacy skills were guided.

Analysis was done using the Statistical Package for the Social Sciences (SPSS, version 12.0; SPSS Inc. 2003). The results were presented in texts and in tables. Bivariate analysis of the relationships between stigma experience and socio-demographic variables was also done using Chi square tests and significance was set at $\mathrm{p}$ value $<0.05$. Currencies are quoted in naira, conversion equivalence in US dollars at the prevailing rate at the time of the study (US $\$ 1=N 120)$. Ethical approval for the study was obtained from the administration of the hospitals and verbally from patients before recruitment for the study.

\section{Results}

\section{Clinical and socio-demographic information}

Of the 205 patients recruited, 102 wee from LASUTH and 103 from IDH. The majority of the patients were male $(123 ; 60 \%)$, with 82 females $(40 \%)$. The mean age was 32.9 years $( \pm 12.3)$. Most patients in the study had attained secondary education or higher $(81 \%)$. Above half of the study population were not married (Table 1).

In both centres, loss of weight was a very common presenting symptom among the patients (51\%- LASUTH; 56\%- IDH). Prolonged cough, the cardinal symptom of tuberculosis, was seen in $61 \%$ of the study population. Most patients were diagnosed with TB less than 2 months prior to the study (Table 1). A sizeable proportion of patients $(98 ; 48 \%)$ earned below the minimum statutory wage of $\$ 7500$ (\$62.5) as recommended by the national government.

Table 1: Clinical and Socio-demographic Information

\begin{tabular}{|c|c|c|c|}
\hline \multirow{3}{*}{$\begin{array}{l}\text { Categories } \\
\text { Sex }\end{array}$} & \multicolumn{2}{|c|}{ Frequency (No.) } & \multirow{2}{*}{$\begin{array}{l}\% \\
60\end{array}$} \\
\hline & Male 1 & 123 & \\
\hline & Female & 82 & 40 \\
\hline \multirow[t]{7}{*}{ Age } & $<10$ years & 2 & 1 \\
\hline & $11-20$ & 22 & 11 \\
\hline & $21-30$ & 77 & 38 \\
\hline & $31-40$ & 56 & 27 \\
\hline & $41-50$ & 29 & 14 \\
\hline & $51-60$ & 12 & 6 \\
\hline & $>60$ & 7 & 3 \\
\hline \multirow[t]{5}{*}{ Education } & None & 10 & 5 \\
\hline & Primary & 31 & 15 \\
\hline & Secondary/ & & \\
\hline & Technical & 95 & 46 \\
\hline & Tertiary & 69 & 34 \\
\hline \multirow[t]{3}{*}{ Religion } & Christianity & y 140 & 68 \\
\hline & Islam & 64 & 31 \\
\hline & Traditional & 1 & 1 \\
\hline \multirow[t]{4}{*}{ Marital status } & ss Single & 110 & 54 \\
\hline & Married & 84 & 41 \\
\hline & Divorced/ & & \\
\hline & Widowed & 11 & 4 \\
\hline Monthly & 7,500 or 1 & less & \\
\hline \multirow[t]{9}{*}{ Income } & $(\$ 62.5$ or less & s) 98 & 48 \\
\hline & 7,501-15, & 5,000 & \\
\hline & $(\$ 62.6-125$ & 5) 66 & 32 \\
\hline & * 15,001-5 & 50,000 & \\
\hline & $(\$ 126-417)$ & 7) 33 & 16 \\
\hline & N $50,001-1$ & 100,000 & \\
\hline & $(\$ 417-833)$ & 3) 4 & 2 \\
\hline & Above $¥ 10$ & 00,001 & \\
\hline & (Above $\$ 83$ & 34) 4 & 2 \\
\hline \multicolumn{4}{|l|}{ Presenting } \\
\hline \multirow[t]{4}{*}{ complaint } & Prolonged co & ough 125 & 61 \\
\hline & Weight loss & 99 & 48 \\
\hline & Bloody sputu & $\mathrm{um}$ & 2 \\
\hline & $\begin{array}{l}\text { Fever, malaise } \\
\text { others }\end{array}$ & se, & 82 \\
\hline \multicolumn{4}{|c|}{ Time since diagnosis } \\
\hline & $<2$ months & 83 & 40 \\
\hline & $3-6$ months & 51 & 25 \\
\hline & 7 - 8month & 40 & 20 \\
\hline & $>8$ months & 31 & 15 \\
\hline
\end{tabular}




\section{TB and social relations}

About $72 \%$ of respondents [147] believed having TB had adversely affected social relationships in their daily life. Of these, TB affected relations with patients' spouses $(27.5 \%)$, family $(38.5 \%)$, friends $(30.5 \%)$ and co-workers $(27.5 \%)$ and this was not mutually exclusive. Only 81 patients [39.5\%] acknowledged enjoying support from family or friends. Thirty-five percent reported reduced attendance of parties and social engagements, and 24\% (49) reported significantly dwindled participation in recreation and sports.

Of the 71 patients who had a current or prior history of smoking, $42 \%$ discontinued smoking on account of TB. Only three percent persisted despite TB infection. Eighty respondents reported a history of alcohol intake, and $41 \%$ of them discontinued on account of TB. However, $9 \%$ persisted in the intake of alcohol.

\section{TB and stigma}

Thirty-seven patients $(18 \%)$ reported a previous experience suggestive of stigma or discrimination. Stigma experience was significantly determined by disclosure of TB status to friends and colleagues. Disclosure of TB status did not significantly determine whether or not patients obtained support from family and friends (Table 2).

Table 2: Disclosure of status and social relations

\begin{tabular}{lccccc}
\hline & Categories & \multicolumn{2}{c}{ Disclosure of TB status } & Chi-square & p-value \\
& & Yes & no & & \\
\hline Stigma experience & Yes & 19 & 18 & 51.457 & $0.000 *$ \\
& No & 10 & 158 & & \\
Support from friends & Yes & 12 & 67 & 0.115 & 0.734 \\
and family & No & 17 & 109 & & \\
\hline
\end{tabular}

*Chi square is significant

Patients presenting with history of weight loss, previous smoking or alcohol history were more likely to experience stigma. Furthermore, stigma experience was more likely among patients who did not attain secondary education or whose monthly income was 15,000 (\$125) or less. Patients in the working age groups [20 - 50years] were more likely to experience stigma. Those unable to work due to clinic attendance were also more likely to experience stigma (Table 3).

Table 3: Significant determinants of stigma experience among TB patients

\begin{tabular}{|c|c|c|c|c|c|}
\hline \multicolumn{2}{|c|}{ Categories } & \multicolumn{2}{|c|}{ Stigma experience } & \multicolumn{2}{|c|}{ Chi-square p-value } \\
\hline & & Yes & no & & \\
\hline \multirow[t]{2}{*}{$\overline{\text { Age }}$} & Below 20yrs, above 50 yrs & 3 & 40 & 4.500 & $<0.05$ \\
\hline & $20-50$ yrs & 34 & 128 & & \\
\hline \multirow{2}{*}{$\begin{array}{l}\text { Feeling of impaired social } \\
\text { relations }\end{array}$} & Yes & 24 & 33 & 30.890 & $<0.001$ \\
\hline & No & 13 & 135 & & \\
\hline \multirow[t]{2}{*}{ History of weight loss } & Yes & 24 & 75 & 4.966 & $<0.05$ \\
\hline & No & 13 & 93 & & \\
\hline \multirow[t]{2}{*}{ Educational attainment } & None/Primary/Technical & 4 & 47 & 4.382 & $<0.05$ \\
\hline & Secondary/University & 33 & 121 & & \\
\hline \multirow[t]{3}{*}{ Monthly income } & * $15000^{1}$ or less & 14 & 74 & 5.339 & $<0.025$ \\
\hline & Above 15000 & 11 & 11 & & \\
\hline & Income not disclosed $^{2}$ & 12 & 83 & & \\
\hline \multirow[t]{2}{*}{ Ability to work on clinic days } & Yes & 11 & 85 & 5.302 & $<0.025$ \\
\hline & No & 26 & 83 & & \\
\hline \multirow[t]{2}{*}{ History of smoking } & Yes & 29 & 42 & 38.162 & $<0.001$ \\
\hline & No & 8 & 126 & & \\
\hline \multirow[t]{2}{*}{ History of alccohol intake } & Yes & 35 & 45 & 58.592 & $<0.001$ \\
\hline & No & 2 & 123 & & \\
\hline
\end{tabular}

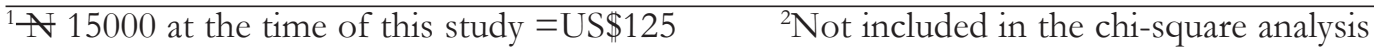


On the contrary, stigma experience was not significantly determined by patient's sex, religion, marital status or ethnic group. Stigma experience was also not significantly determined by the centre at which the patient was receiving care (Table 4).

Table 4: Relationships with stigma experience among TB patients that were not statistically significant

\begin{tabular}{llcccc}
\hline & Categories & \multicolumn{2}{c}{ Stigma experience } & Chi-square & p-value \\
\cline { 3 - 4 } & & \multicolumn{1}{c}{ Yes } & No & & \\
\hline Gender & Female & 14 & 68 & .088 & $>0.5$ \\
& Male & 23 & 100 & & \\
Religion & Christianity & 26 & 114 & .278 & $>0.5$ \\
& Islam & 11 & 53 & & \\
& Traditional & 0 & 1 & & $>0.25$ \\
Marital Status Single & 19 & 91 & 3.680 & \\
$\quad$ Married & 17 & 67 & & \\
& Divorced & 1 & 1 & & \\
& Widowed & 0 & 9 & & \\
Tribe/ethnicity Yoruba & 20 & 96 & 4.613 & \\
& Igbo & 4 & 24 & & \\
& Hausa & 1 & 5 & & \\
& North-central & 1 & 13 & & \\
& South-south & 11 & 28 & & \\
North-East & 0 & 2 & & \\
Chest Clinic & LASUTH & 17 & 85 & 0.262 & \\
Attended & IDH & 20 & 83 & & \\
\hline
\end{tabular}

\section{Discussion}

Stigma faced by TB patienss is vague and not easily assessed ${ }^{11}$.Weight loss is a common presenting feature to TB and HIV/AIDS, making it possible for people to conflate both diseases ${ }^{12}$. Up to $48 \%$ of patients presented with weight loss in this stud. This was less than the $73 \%$ obtained by Odusanya et al in their study of patients in LASUTH in $2004^{13}$. In the current study, weight loss was found to be a significant determinant of stigma experience. Studies in Thailand using focus groups among health centre staff, TB patients with or without HIV and HIV patients observed that the increased awareness of HIV/AIDS may be a cause of delays in presenting in the clinic for TB treatment. ${ }^{14}$ Similar observations were made by investigators in London studying African patients. ${ }^{15}$ More so, pulmonary tuberculosis is regarded by the World Health Organisation (WHO) as an AIDS-indicator condition. ${ }^{16}$ This complicated relationship between HIV/AIDS and TB exposes TB patients to stigma. Further, TB patients with more severe symptoms have been reported in Thailand to have experienced greater stigma. $^{12}$

Most patients understand TB through the medical model and perceive themselves as disease vectors ${ }^{17}$. In our study, TB was observed as affecting relations with patients' spouses and their family, as well as with friends and co-workers. Many patients did not disclose their TB status, in anticipation of stigma experience, which they believed to be a corollary of disclosure. Unfortunately, most of those who disclosed were stigmatised. The London study reported actual stigma experiences to be rare, although patients felt stigmatised by the diagnosis itself ${ }^{15}$. 'External' or 'enacted' stigma is rooted mainly in fear and judgment of what is different, leading to blame, distancing, and discrimination. 'Internal stigma' - also described as felt, imagined, or self stigma - is the product of the internalization of shame, blame, hopelessness, guilt, and fear of discrimination. ${ }^{18}$ One U.S. study found that internal stigma contributes significantly to levels of depression, anxiety, and hopelessness in people living with HIV ${ }^{18}$. These may lead to diagnostic and treatment delays as well as noncompliance to treatment schedule, treatment failures and, possibly, drug resistance.

Stigma experience was more common among patients in the working age groups [2050 years], on lower rungs of the socioeconomic ladder, with limited education and those who miss 
work due to clinic attendance. In the London study, experience of TB in a known person was found to mitigate stigma. ${ }^{14}$ Patients' present or previous habits, especially those with a possible social impact, like smoking and alcohol consumption also affected their stigma experience.

\section{Conclusion}

The self-reported experience of stigma among TB patients in this study was significant. Weight loss, low socio-economic status, current or previous smoking or alcohol consumption and disclosure of TB status were identified as significant socio-demographic determinants of stigma among TB patients. Patients' work conditions may also have an impact on stigma experience.

\section{Recommendations}

Health workers should pay closer attention to counselling patients who face the risk of stigma. The significance of disclosure should be discussed carefully with them. Local health agencies, as an extension of direct observation, may create support groups and forums for patients to share experiences. This is a practical way to mollify the stigma experience of patients, this may improve treatment adherence and contribute to disease control. Further research is required to explore the relationship between weight loss and stigma experience among tuberculosis patients.

\section{References}

1. Lucas AO, Gilles HM. Short Textbook of Public Health for the Tropics. $4^{\text {th }}$ ed. London: BookPower; 2003 p. 159

2. World Health Organisation (WHO). World Health Statistics 2008. Geneva (Switzerland). Available from http://www.who.int/whosis/ whostat/EN_WHS08_Full.pdf

3. WHO. Global Report on tuberculosis control 2007. Geneva. Available from http:// www.who.int/tb/publications/global_report/ 2007/pdf/key_findings.pdf

4. Westaway MS, Wolmarans L. Cognitive and affective reactions of black urban South Africans towards tuberculosis. Tuber Lung Dis. 1994; 75(6):447-53.

5. Connolly M, Nunn P. Women and Tuberculosis. World Health Stat Q. 1996; 49(2):115-9

6. Baral SC, Karki DK, Newell JN. Causes of stigma and discrimination associated with tuberculosis in Nepal: a qualitative study. BMC
Public Health 2007. 7:211.doi:10.1186/14712458-7-211.

7. Jaramillo E. Tuberculosis and Stigma: Predictors of Prejudice Against People with Tuberculosis. J Health Psych 2009;4(1):71-79

8. Microsoft Encarta English Dictionary. Encarta Premium [DVD]; 2009. Discrimination

9. Lienhardt C, Ogden JA. Tuberculosis control in poor countries. Trop Med Int Health 2004; 9(7):833-841

10. Demissie M, Getahun H, Lindtj $\varnothing$ rn B. Community tuberculosis care through "TB clubs" in rural north Ethiopia. Soc Sci Med 2003; 56:2009-2018

11. Macq J, Solis A, Martinez G. Assessing the stigma of tuberculosis. Psych Health Med 2006; 11(3):346-352(7)

12. Sengupta S. Social impact of tuberculosis in southern Thailand: views from patients, care providers and the community. Int J Tuberc Lung Dis 2006; 10(9):1008-1012(5)

13. Odusanya OO, Babafemi JO. Patterns of delays amongst pulmonary tuberculosis patients in Lagos, Nigeria. BMC Public Health 2004. 4:18. doi:10.1186/1471-2458-4-18

14. Ngavithayong J, Winkvist A, Diwan V. High HIV/AIDS awareness causing TB delays. AIDS 2000. 14:1413-1419

15. Nnoaham KE, Pool R, Bothamley, G, Grant AD. Perceptions and experiences of tuberculosis among African patients attending a tuberculosis clinic in London. Int J Tuberc Lung Dis 2006; 10(9):1013-1017(5).

16. Fauci AS, Lane HC. Human Immunodeficiency Virus Disease: AIDS and Related Disorders. In: Fauci AS, Braunwald E, Kasper DL, Hauser SL, Longo DL, Jameson JL. Harrison's Principles of Internal Medicine [DVD]. 17th ed. 2008. McGraw Hill Companies Inc

17. Kelly P. Isolation and Stigma: the experience of patients with active TB. J Comm Health Nursing 1999; 16(4):233-241

18. Brouard P, Wills C. A closer look: Internalization of stigma related to HIV. US Agency for International Development POLICY Project. Washington. Jan 2006. Available from http:// www.policyproject.com/pubs/generalreport/ Internal_Stigma.pdf 